ARTICLE OPEN

\title{
The insect antimicrobial peptide cecropin A disrupts uropathogenic Escherichia coli biofilms
}

\author{
Miriam Kalsy ${ }^{1,7}$, Miray Tonk ${ }^{2,3}$, Martin Hardt ${ }^{4}$, Ulrich Dobrindt ${ }^{5}$, Agnieszka Zdybicka-Barabas (D) ${ }^{6}$, Malgorzata Cytrynska ${ }^{6}$, \\ Andreas Vilcinskas ${ }^{1,2,3 凶}$ and Krishnendu Mukherjee ${ }^{1,5,7 凶}$
}

Current antibiotics cannot eradicate uropathogenic Escherichia coli (UPEC) biofilms, leading to recurrent urinary tract infections. Here, we show that the insect antimicrobial peptide cecropin A (CecA) can destroy planktonic and sessile biofilm-forming UPEC cells, either alone or when combined with the antibiotic nalidixic acid (NAL), synergistically clearing infection in vivo without offtarget cytotoxicity. The multi-target mechanism of action involves outer membrane permeabilization followed by biofilm disruption triggered by the inhibition of efflux pump activity and interactions with extracellular and intracellular nucleic acids. These diverse targets ensure that resistance to the CecA + NAL combination emerges slowly. The antimicrobial mechanisms of CecA, thus, extend beyond pore-forming activity to include an unanticipated biofilm-eradication process, offering an alternative approach to combat antibiotic-resistant UPEC infections.

npj Biofilms and Microbiomes (2020)6:6; https://doi.org/10.1038/s41522-020-0116-3

\section{INTRODUCTION}

Uropathogenic Escherichia coli (UPEC) causes up to $90 \%$ of all urinary tract infections (UTIs) in humans, and antibiotics remain the primary therapeutic option despite the spread of resistance among UPEC strains. ${ }^{1}$ Treatment is challenging because UPEC can form biofilms in the bladder epithelial cells and also on the surface of urinary catheters. ${ }^{2}$ Biofilm-forming UPEC cells are highly resistant to current antibiotics because the doses have been optimized to kill planktonic cells. ${ }^{3}$ UPEC biofilms use multiple strategies to resist antibiotics, including extracellular appendages, an impenetrable extracellular matrix (ECM), persister cells, efflux pumps, and quorum sensing. ${ }^{3}$ Anti-biofilm drugs must overcome all these barriers and achieve broad-spectrum activity against both planktonic and biofilm-forming UPEC cells without adverse effects.

Antimicrobial peptides (AMPs) are promising candidates for biofilm eradication given their novel mechanisms of action against planktonic cells, which reduce the likelihood of resistance evolving compared to the use of antibiotics. ${ }^{4}$ Furthermore, combinations of AMPs and traditional antibiotics with different mechanisms of action could facilitate the revival of ineffective drugs based on the enhanced or synergistic activity of the combination against human pathogens. ${ }^{5}$ However, most AMPs have not been tested to determine their ability to inhibit biofilm formation by UPEC strains, and careful re-screening is therefore necessary to identify promising candidates.

In this study, we screened insect AMPs for anti-biofilm activities and found that cecropin A (CecA) from the greater wax moth Galleria mellonella can eradicate biofilms formed by UPEC strains. We tested combinations of this AMP with the antibiotic nalidixic acid (NAL) in vitro and in vivo to determine the potential for synergistic interactions. We also investigated the ability of CecA to interact with multiple extracellular and intracellular targets that are important for anti-biofilm drug discovery.

\section{RESULTS AND DISCUSSION}

Testing the synergistic antibacterial activity of CecA and NAL against UPEC cells

When screening insect AMPs against UPEC strains, we discovered the "biofilm-busting" activity of CecA, a linear cationic a-helical peptide from the greater wax moth Galleria mellonella. The minimum inhibitory concentration (MIC) of CecA against the planktonic UPEC strain CFT073 was high, so we tested combinations of this AMP with the antibiotic nalidixic acid (NAL) in a checkerboard assay to identify synergistic interactions. The absolute MIC decreased from 100 to $50 \mu \mathrm{g} / \mathrm{ml}$ for CecA, and from $60 \mu \mathrm{g} / \mathrm{ml}$ to $0.5 \mathrm{ng} / \mathrm{ml}$ for $\mathrm{NAL}$, indicating their synergistic activity (Fig. $1 \mathrm{a}$ and Supplementary Fig. 1). This was confirmed by calculating the fractional inhibitory concentration (FIC $<0.5)$. We selected the combination of $50 \mu \mathrm{g} / \mathrm{ml} \mathrm{CecA}$ and $0.5 \mathrm{ng} / \mathrm{ml}$ NAL for further analysis because it is the minimum CecA and NAL concentration, respectively, that is ineffective as monotherapy but can synergistically interact to completely inhibit the growth of planktonic UPEC cells. The antimicrobial concentrations of CecA $(50 \mu \mathrm{g} / \mathrm{ml}), \mathrm{NAL}(0.5 \mathrm{ng} / \mathrm{ml})$ and their combination showed no significant toxicity toward erythrocytes $(\mathrm{Cec} A<$ $1.5 \%, \mathrm{NAL}<2.5 \%, \mathrm{CecA}+\mathrm{NAL}<2.5 \%$ ) or fibroblasts (CecA $<8 \%$, $\mathrm{NAL}<10 \%$, CecA + NAL $<11 \%$ ), suggesting that CecA is suitable for further therapeutic development (Fig. 1b, c). However, cytotoxicity was slightly increased with $75 \mu \mathrm{g} / \mathrm{ml}$ of CecA (Fig. 1c). We therefore investigated the efficacy of CecA in vivo using our G. mellonella-UPEC infection model ${ }^{6}$ with or without NAL (Fig. 1d-f). G. mellonella is an ideal replacement for rodents and other mammalian infection models because the larvae can be reared at $37^{\circ} \mathrm{C}$ and are susceptible to many different human pathogens, but large numbers of insects can be reared and tested inexpensively without ethical restrictions, providing extremely robust and statistically significant in vivo

\footnotetext{
${ }^{1}$ Fraunhofer Institute for Molecular Biology and Applied Ecology, Department of Bioresources, 35394 Giessen, Germany. ${ }^{2}$ Institute for Insect Biotechnology, Justus Liebig University, 35392 Giessen, Germany. ${ }^{3}$ LOEWE Centre for Translational Biodiversity Genomics (LOEWE-TBG), 60325 Frankfurt, Germany. ${ }^{4}$ Imaging Unit, Biomedical Research Center Seltersberg (BFS), Justus Liebig University, 35392 Giessen, Germany. ${ }^{5}$ Institute of Hygiene, University of Muenster, 48149 Muenster, Germany. ${ }^{6}$ Department of Immunobiology, Institute of Biological Sciences, Faculty of Biology and Biotechnology, Maria Curie-Skłodowska University, Lublin, Poland. ${ }^{7}$ These authors contributed equally: Miriam Kalsy, Krishnendu Mukherjee ${ }^{凶}$ email: Andreas.Vilcinskas@agrar.uni-giessen.de; Krishnendu.Mukherjee@ukmuenster.de
} 

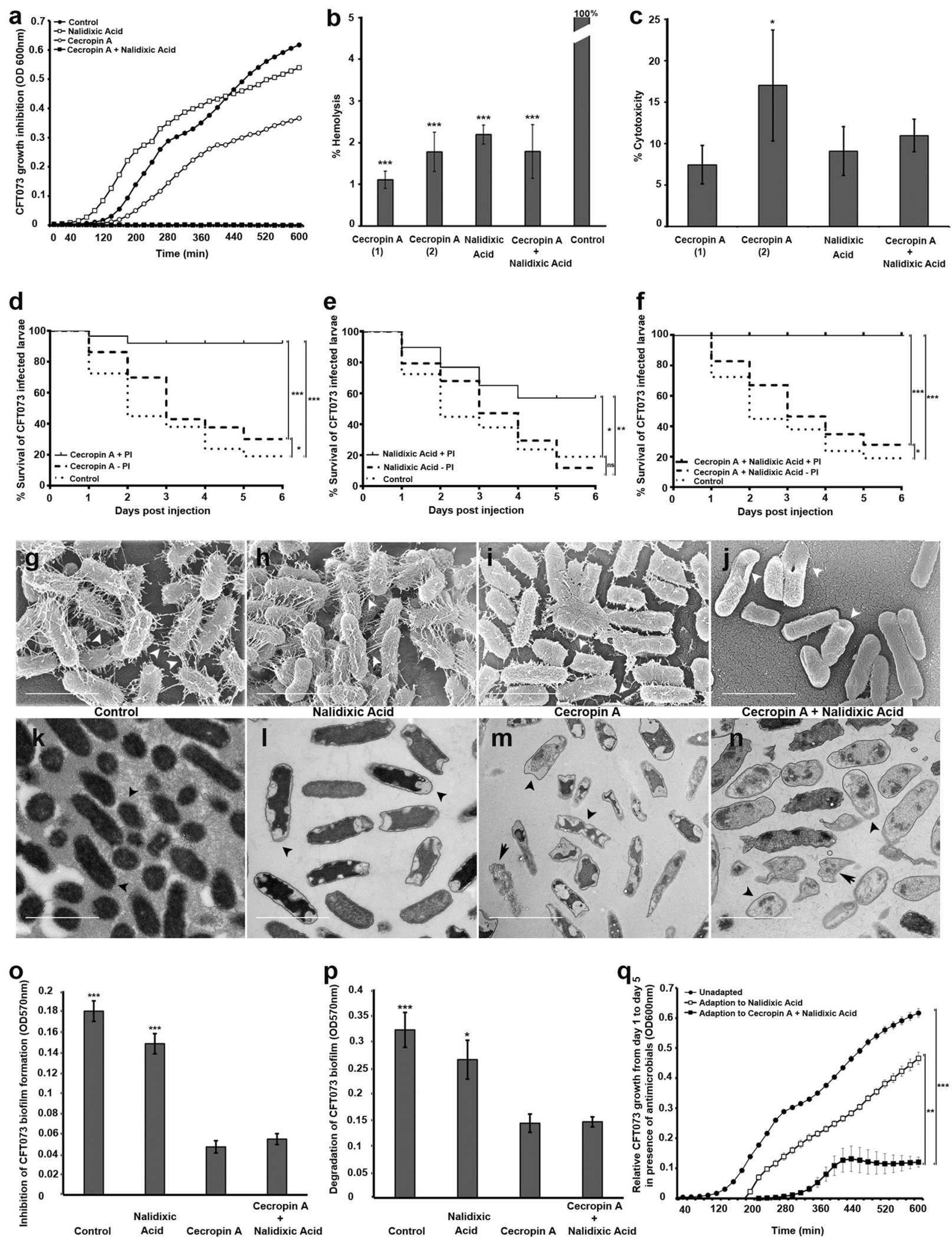

data. ${ }^{6}$ CecA \pm NAL slightly improved the survival of CFT073infected larvae but NAL alone had no effect (Fig. 1d-f). CFT073 survival in infected larvae was reduced more significantly by the combination of $50 \mu \mathrm{g} / \mathrm{ml} \mathrm{CecA}$ and $0.5 \mathrm{ng} / \mathrm{ml} \mathrm{NAL}$ compared to individual treatments (Supplementary Fig. 2).
AMPs are proteolytically degraded in vivo so we added a protease inhibitor to improve the therapeutic efficacy of CecA. ${ }^{7}$ Toxicity of fibroblast cells was slightly increased by the CecA + NAL combination in presence of the protease inhibitor (Supplementary Fig. 3a, b). We found that more of the infected larvae 
Fig. 1 Effect of synergy between cecropin A (CecA) and nalidixic acid (NAL) on planktonic and biofilm-forming uropathogenic Escherichia coli cells. a Time-kill curves of CecA $(50 \mu \mathrm{g} / \mathrm{ml})$, NAL $(0.5 \mathrm{ng} / \mathrm{ml})$, and their combination against strain CFT073. Cells were treated with CecA $1(50 \mu \mathrm{g} / \mathrm{ml})$, CecA $2(75 \mu \mathrm{g} / \mathrm{ml})$, NAL $(0.5 \mathrm{ng} / \mathrm{ml})$, or CecA $(50 \mu \mathrm{g} / \mathrm{ml})+\mathrm{NAL}(0.5 \mathrm{ng} / \mathrm{ml})$ to determine b hemolysis of porcine erythrocytes in comparison to $10 \%$ Triton X-100 (control), and $\mathbf{c}$ the viability of BHK-21 fibroblast in comparison to untreated control. Kaplan-Meier plots of CFT073-infected G. mellonella survival after treatment with d CecA $(50 \mu \mathrm{g} / \mathrm{ml})$, e NAL $(0.5 \mathrm{ng} / \mathrm{ml})$, and f their combination $+/-$ protease inhibitor (PI). $\mathbf{g}-\mathbf{j}$ Scanning and $\mathbf{k}-\mathbf{n}$ transmission electronic microscopy analysis of biofilm structures formed by CFT073 following treatment with CecA $(50 \mu \mathrm{g} / \mathrm{ml}) \pm \mathrm{NAL}(0.5 \mathrm{ng} / \mathrm{ml})$. g-n The biofilm-containing discs were supplemented with $\mathbf{h}, \mathbf{I}$ NAL, i, $\mathbf{m}$ CecA, or $\mathbf{j}$, $\mathbf{n}$ their combination in fresh LB medium and incubated for another $24 \mathrm{~h}$. Biofilm-forming discs grown in LB medium without supplements were used as controls $(\mathbf{g}, \mathbf{k})$. Representative images are shown (scale bar $=2 \mu \mathrm{m})$. White arrow heads show intercellular filaments ( $\mathbf{g}-\mathbf{j})$, black short arrow heads indicate cytoplasm density (k-n), and black arrows show cell debris $(\mathbf{m}, \mathbf{n})$. o Percentage inhibition of CFT073 biofilms by NAL (0.5 ng/ml) or CecA $(50 \mu \mathrm{g} / \mathrm{ml})$ compared to their combination after $48 \mathrm{~h}$. p Percentage eradication of pre-formed CFT073 biofilms by NAL (0.5 ng/ml) or CecA $(50 \mu \mathrm{g} / \mathrm{ml})$ compared to their combination. q CFT073 adaptation to NAL $(20 \mu \mathrm{g} / \mathrm{ml})$ or the CecA $(20 \mu \mathrm{g} / \mathrm{ml})+\mathrm{NAL}(0.5 \mathrm{ng} / \mathrm{ml})$ combination was determined by analyzing bacterial growth after repeated exposure to antimicrobials for 5 days. The figure represents bacterial growth at day 5 with reference to day 1 after antimicrobial exposure. Values are means with standard errors: $n=4$ (panels a and q), $n$ $=3$ (panels $\mathbf{b}-\mathbf{f}$ and $\mathbf{0}-\mathbf{p}$ ). Significance was determined by one-way ANOVA, Dunnett's multiple comparison test (b, $\mathbf{c}$, $\mathbf{0}, \mathbf{p})$, Holm-Šídák correction $(\mathbf{q})\left({ }^{*} P<0.05 ;{ }^{*} P<0.005 ;{ }^{* *} P<0.0005\right)$.

survived when the protease inhibitor was present (Fig. 1d-f). We then analyzed the expression of genes regulating phases I and III of drug metabolism in G. mellonella larvae to determine whether the protease inhibitor affected the pharmacokinetic properties of the combined treatment in vivo (Supplementary Table 1). We selected genes encoding cytochrome P450, alcohol dehydrogenase, NADH-ubiquinone oxidoreductase, carboxylic ester hydrolase, epoxide hydrolase (phase I), and the efflux transporter ATPbinding cassette proteins (phase III) that are responsible for drug metabolism. These genes were significantly upregulated in infected larvae $1 \mathrm{~h}$ following a single dose of the combined treatment compared to the AMP without the protease inhibitor (Supplementary Fig. 3c, d). This indicated increased metabolic activities in larvae possibly due to sustained therapeutic efficacy of CecA because of the presence of the protease inhibitor. Furthermore, the protease inhibitor could inhibit protease activity in G. mellonella hemolymph by $>50 \%$ (Supplementary Fig. 3e). Based on these pharmacokinetic parameters, we selected $50 \mu \mathrm{g} /$ $\mathrm{ml} \mathrm{CecA}$ and $0.5 \mathrm{ng} / \mathrm{ml} \mathrm{NAL}$ as the most suitable dose to investigate the viability and membrane integrity of planktonic and biofilm-forming CFT073 cells.

Effects of CecA on the viability and structure of biofilm-forming UPEC cells

We determined the viability of cells using the vital stain SYTO 9, which binds to living cells with intact membranes and stains them green, and propidium iodide, which specifically penetrates cells with damaged membranes and stains them red. Planktonic CFT073 cells treated with dimethyl sulfoxide as a control were stained green but the proportion of red cells increased progressively following treatment with NAL, CecA, and CecA + NAL, respectively (Supplementary Fig. $4 a-d$ ). Bacterial surface was less granular with damaged envelopes and recesses following CecA treatment indicating loss of membrane integrity in comparison to untreated E. coli cells (Supplementary Fig. 5 and Supplementary Table 2). We observed up to $15 \%$ permeabilization of the bacterial membrane by CecA at the final concentration range of $0.25 \mu \mathrm{M}-1 \mu \mathrm{M}$ (Supplementary Fig. 5a-e). Cecropins in contrast to NAL permeabilize bacteria by initial binding to outer membrane components like lipopolysaccharides (LPS) ${ }^{5}$ in Gramnegatives, and accordingly, we found that the combination of CecA + NAL caused a significant increase in cell permeability, reflecting their synergistic activity.

Electron microscopy revealed that $C e c A \pm N A L$ prevents the development of UPEC biofilms by targeting UPEC adhesive filaments, specifically type $I$ and $P$ fimbriae (Fig. $1 \mathrm{~g}-\mathrm{j}$ ), that facilitate the permanent attachment of biofilm-forming cells to surfaces and limit contact between AMPs and bacterial membranes. $^{3}$ Control and NAL-treated CFT073 biofilms were visually indistinguishable, featuring complex networks of rod-shaped cells
(Fig. 1g, h). However, treatment with $C e c A \pm N A L$ destroyed this network, resulting in the collapse and subsequent disruption of the bacterial membrane (Fig. 1i, j). These treatments also caused changes in the structure of the polymeric ECM, cell envelope, and cytoplasmic density of the UPEC cells compared to controls (Fig. $1 \mathrm{k}-\mathrm{n}$ ). The severity of the damage was greatest for the CecA \pm NAL treatment, and included an irregular shape, damaged outer membranes, large sites of cytoplasmic clearing, and cell debris (Fig. $1 \mathrm{~m}, \mathrm{n}$ ). These data indicate that $\mathrm{Cec} A \pm N A L$ inhibits planktonic cells of different UPEC strains (CFT073 and 536) and also degrades surface-associated biofilms of these strains, probably by enhancing the diffusion of NAL into the cell (Fig. 10, p and Supplementary Fig. 6a-f). This is likely to limit the opportunity for UPEC cells to evolve resistance against CecA, which forms pores in the bacterial membrane, as this would require simultaneous alterations to multiple biochemical pathways related to cell membrane modifications. ${ }^{8,9}$

UPEC adaptation to the combination of CecA + NAL

We next considered whether UPEC can adapt to the combined drug treatment and tested this by exposing CFT073 cells to sublethal concentrations of CecA $(20 \mu \mathrm{g} / \mathrm{ml})$ and NAL $(0.5 \mathrm{ng} / \mathrm{ml})$ repeatedly for 5 days. We then compared the adapted UPEC population (day 5 ) to the ancestral population (day 1 ) by exposing them both the same combination dose (Fig. 1q). A similar strategy was followed with sublethal concentrations of NAL alone $(20 \mu \mathrm{g} /$ $\mathrm{ml})$. Repeated exposure to the combination of CecA + NAL led to a significant decline in bacterial fitness, as shown by the slow recovery of growth on day 5 compared to cells treated with NAL alone. This indicated that CFT073 cells take longer to evolve resistance against the CecA + NAL combination than to the antibiotic alone. ${ }^{4}$ Future research should address whether the delayed resistance to the CecA + NAL combination is mediated by CecA targeting a single or multiple bacterial components.

Identification of extracellular and intracellular targets of CecA in biofilm-forming UPEC cells

The antimicrobial resistance of bacterial biofilms is mediated by multiple factors including energy-dependent multidrug resistance efflux pumps and extracellular DNA (eDNA), a component of the ECM. $^{10-13}$ We used fluorescent dyes with different emission wavelengths depending on their location (intracellular or extracellular) to measure the accumulation, efflux and eDNA-binding capacity of CecA in CFT073 cells. ${ }^{14,15}$ Non-inhibitory antimicrobial concentrations were selected to study the accumulation of the peptide and the efflux activity, thus preventing changes in fluorescence intensity due to the loss of membrane integrity. Biofilm- forming UPEC cells were incubated with $10 \mu \mathrm{g} / \mathrm{ml} \mathrm{CecA}$ or $0.5 \mathrm{ng} / \mathrm{ml} \mathrm{NAL}$ in the presence of $2.5 \mu \mathrm{M} \mathrm{H} 33342$, a DNA- 


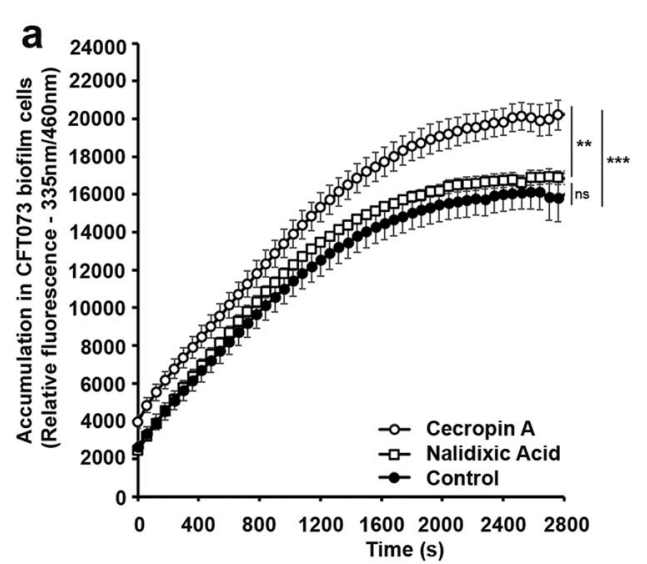

C

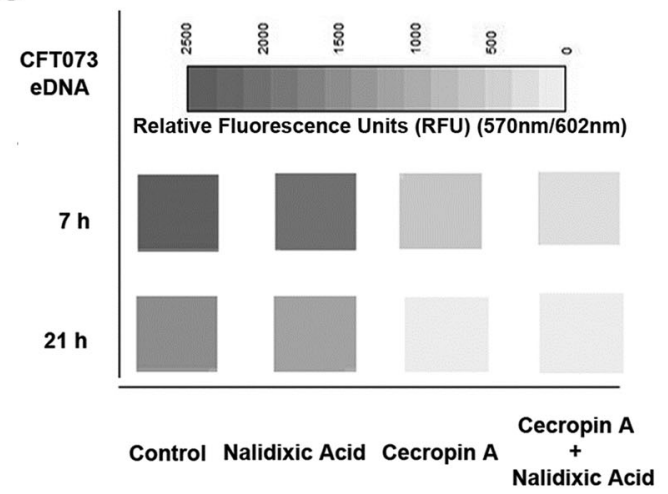

e

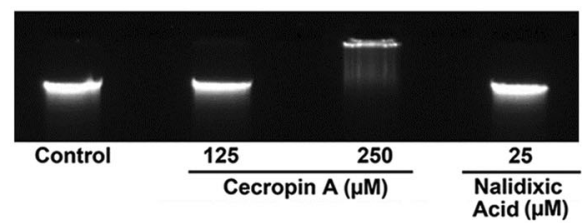

b

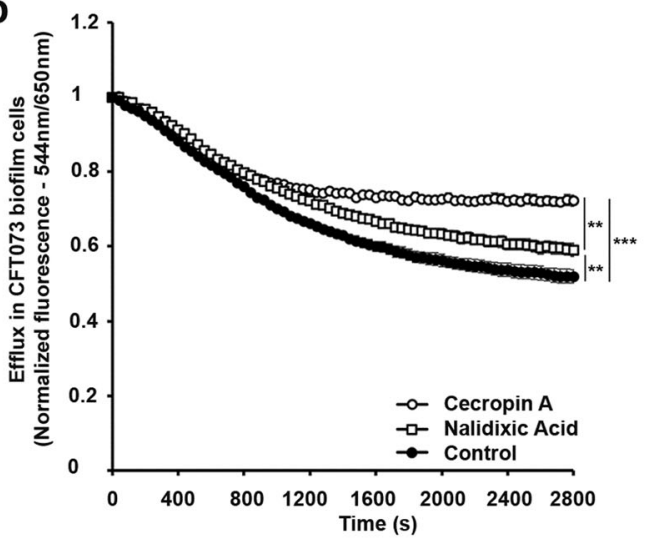

d

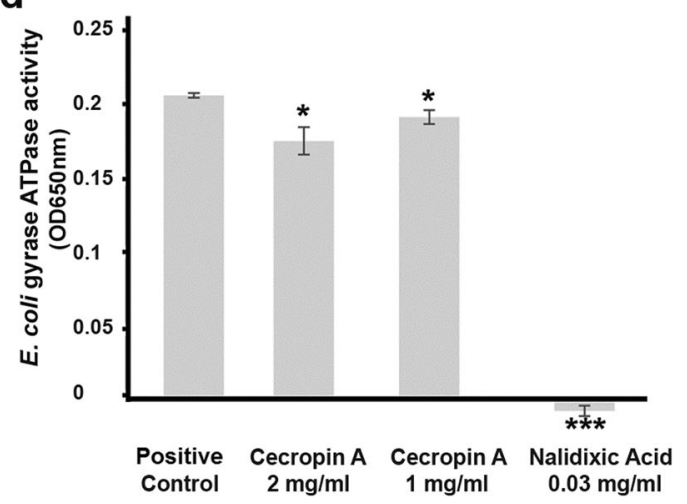

f

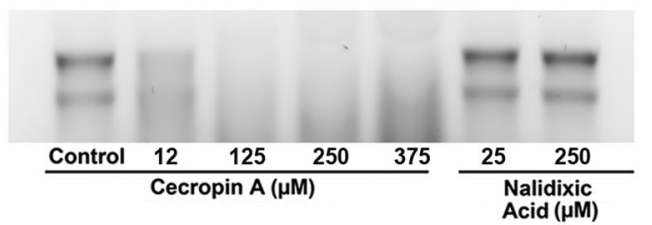

Fig. 2 Molecular targets of cecropin A (CecA) in uropathogenic Escherichia coli cells. a Steady-state levels of H33342 (2.5 $\mu$ M) accumulating in CFT073 biofilm cells with and without exposure to CecA $(10 \mu \mathrm{g} / \mathrm{ml})$ or nalidixic acid (NAL; $0.5 \mathrm{ng} / \mathrm{ml})$. $\mathbf{b}$ Inhibition of Nile red efflux by CecA $(10 \mu \mathrm{g} / \mathrm{ml})$ and NAL $(0.5 \mathrm{ng} / \mathrm{ml})$. Efflux was triggered at $100 \mathrm{~s}$ by the addition of $20 \mathrm{mM}$ glucose. The intensity of fluorescence emission from Nile red was presented to show the effects of CecA, NAL or the absence of treatment in CFT073 biofilm cells. c Decreasing intensities of the fluorescent dye BOBO-3 that cannot penetrate intact membranes and consequently only stains external nucleic acids were measured following incubation with untreated CFT073 cells or those treated with NAL $(0.5 \mathrm{ng} / \mathrm{ml}), \mathrm{CecA}(50 \mu \mathrm{g} / \mathrm{ml})$ or their combination. d Inhibition of E. coli DNA gyrase ATPase activity by CecA and NAL. Decreasing intensities of eDNA and $\mathbf{f}$ RNA bands from CFT073 cells treated with a high concentration of CecA were visualized by gel electrophoresis to highlight the DNA/RNA-binding activity of CecA. Values are means and standard errors: $n=3$ (panels $\mathbf{a}, \mathbf{b}$, and $\mathbf{d}$ ). Significance was determined by one-way ANOVA and Holm-Šídák correction (a, b), Dunnett's multiple comparison test (d) $\left({ }^{*} P<0.05 ;{ }^{*} P<0.005 ;{ }^{* *} P<0.0005\right.$; ns - not significant).

intercalating fluorescent dye. Similarly, we incubated exponentialphase CFT073 cells (planktonic cells) with $1 \mu \mathrm{g} / \mathrm{ml}$ CecA or $0.5 \mathrm{ng} /$ $\mathrm{ml} \mathrm{NAL}$ in the presence of $2.5 \mu \mathrm{M} \mathrm{H33342.} \mathrm{CecA} \mathrm{caused} \mathrm{a}$ significant increase in $\mathrm{H} 33342$ accumulation by both planktonic cells and UPEC biofilm compared to NAL and the untreated control (Fig. 2a and Supplementary Fig. 7a). We also measured the efflux of the lipophilic dye Nile red, which emits a stronger signal when bound to membrane phospholipids and is therefore ideal for the investigation of resistance-nodulation-division (RND) efflux pumps. ${ }^{14}$ We detected a stronger fluorescent signal in the presence of CecA compared to NAL and the untreated control, indicating that dye efflux was inhibited by CecA (Fig. $2 \mathrm{~b}$ and Supplementary Fig. 7b). Dye efflux was inhibited in biofilm and planktonic UPEC cells in presence of $10 \mu \mathrm{g} / \mathrm{ml}$ and $1 \mu \mathrm{g} / \mathrm{ml} \mathrm{CecA}$, respectively (Fig. 2b and Supplementary Fig. $7 b, c)$. Similarly, we stained CFT073 biofilms with BOBO-3, which selectively binds
eDNA, and screened for changes in fluorescence caused by dye displacement. We observed a decrease in fluorescence intensity when CFT073 was incubated with $50 \mu \mathrm{g} / \mathrm{ml}$ CecA $\pm 0.5 \mathrm{ng} / \mathrm{ml} \mathrm{NAL}$ for 7 or $21 \mathrm{~h}$, indicating that CecA inhibits the release of eDNA. In contrast, NAL alone had no effect on the signal and thus does not appear to influence the release of bacterial eDNA (Fig. 2c). These data confirm that the degradation of UPEC biofilms is promoted by the suppression of efflux, the uptake of more CecA, and its ability to bind eDNA.

Next, we investigated the interaction between CecA and other UPEC intracellular targets (genomic DNA and total RNA). E. coli DNA gyrase ATPase activity, which is required for DNA supercoiling and decatenation, was inhibited strongly by NAL but only weakly by CecA (Fig. 2d). Using the limbo server, we predicted that CecA would bind to the WKIFKKI sequence of DnaK (score $=13.4$ ), but we found no evidence that the peptide inhibits the ATPase 
activity of DnaK (Supplementary Fig. $7 d$ ). ${ }^{16}$ We also predicted the presence of DNA/RNA-binding residues in CecA using DP-Bind and FastRNABindR (Supplementary Tables 3 and 4). We observed the concentration-dependent displacement of DNA (Fig. 2e and Supplementary Fig. 8) and RNA (Fig. 2f and Supplementary Fig. 9) by high doses of CecA. Taken together, our data show that CecA is a biofilm-busting AMP and that its multi-target mechanisms of action make it suitable as a lead for the development of new drugs that eradicate biofilm-forming UPEC strains.

\section{METHODS}

Peptides, bacterial strains, and culture conditions

CecA is 39 amino acids long (KWKIFKKIEKAGRNIRDGIIKAGPAVSVVGEAATIYKTG) and was synthesized by Pepmic, Jiangsu, China. NAL was sourced from Sigma-Aldrich (St. Louis, Missouri, USA). We tested the UPEC strains CFT073 (pyelonephritis isolate) and 536 (cystitis isolate) that were susceptible to all clinically used antibiotics. Bacterial cultures were maintained aerobically in lysogeny broth (LB) medium (Carl Roth, Karlsruhe, Germany) at $37^{\circ} \mathrm{C}$ and on LB agar plates. For long-term storage, bacteria were frozen at $-80^{\circ} \mathrm{C}$ in LB medium supplemented with $30 \%$ glycerol.

\section{Inhibition of bacterial growth}

Logarithmic growth phase bacterial cultures in $10 \mathrm{ml}$ LB were diluted to a final $\mathrm{OD}_{600}$ of $\sim 0.002$ and MICs were determined using the broth microdilution method in 96-well microtiter plates with an assay volume of $200 \mu \mathrm{l}$. Briefly, serial dilutions of NAL (final concentration $60-0.0005 \mu \mathrm{g} /$ $\mathrm{ml}$ ) and CecA (final concentration $0.5-100 \mu \mathrm{g} / \mathrm{ml}$ ) were transferred to the microtiter plate and incubated overnight at $37^{\circ} \mathrm{C}$. We then measured the absorbance at $600 \mathrm{~nm}$ to determine growth inhibition as an indicator of antimicrobial activity. The MIC was defined as the minimum concentration at which no bacterial growth was observed in each well.

\section{Checkerboard assay}

The synergy between CecA and NAL was tested using a checkerboard assay. ${ }^{17}$ Bacterial suspensions were prepared at a final concentration of $5 \times$ $10^{5} \mathrm{CFU} / \mathrm{ml}$. The two compounds for combinatorial testing were arrayed as serial dilutions, vertically for one compound and horizontally for the other, in the same 96-well microplate. The assay was carried out in triplicate as described above for the measurement of individual MICs. The FIC indices were calculated according to the following formulae: $\mathrm{FIC}=X / \mathrm{MICX}$, and FIC index $=\mathrm{FIC}_{\mathrm{CecA}}+\mathrm{FIC}_{\mathrm{NAL}}$, where $X$ is the lowest inhibitory concentration of the drug in the presence of the co-drug. A FIC index of $<0.5$ indicates synergy between the test compounds. ${ }^{18}$

\section{Time-kill curve}

A time-kill assay was carried out in triplicate, in non-cation-adjusted LB according to the protocol from the Clinical and Laboratory Standards Institute (Wayne, Pennsylvania, USA). An overnight bacterial culture was diluted in LB medium to an absorbance of 0.05 at $600 \mathrm{~nm}$. Different concentrations of test compounds (CecA, NAL, or CecA $+N A L)$ were then added, and the culture was incubated at $37{ }^{\circ} \mathrm{C}$ with shaking.

\section{Hemolytic and cytotoxicity assay}

The hemolytic activities of the test compounds were determined with assay volumes of $100 \mu \mathrm{ul}^{19}$ Erythrocytes were harvested by centrifugation at $1500 \times g$ for $3 \mathrm{~min}$ at $4{ }^{\circ} \mathrm{C}$ and washed three times in phosphate-buffered saline (PBS). A suspension of the erythrocytes was prepared with a dilution factor of 1:10 in PBS. Test compounds with or without a broad-spectrum protease inhibitor cocktail (final concentration 0.0007x) (Sigma-Aldrich) that selectively inhibits cysteine and serine proteases but not metalloproteases or aspartic proteases, were incubated with the erythrocyte suspension for $1 \mathrm{~h}$ at $37^{\circ} \mathrm{C}$ in a 96-well plate. Percentage hemolysis of the test compounds was calculated in comparison to $10 \%$ Triton X-100 (positive control).

Cytotoxicity was evaluated using the baby hamster kidney fibroblast cell line BHK-21 (Chromotek, Planegg-Martinsried, Germany). ${ }^{20}$ The cells were grown in the presence of Dulbecco's modified Eagle's medium (DMEM) supplemented with $4.5 \mathrm{~g} / \mathrm{l}$ glucose, $110 \mathrm{mg} / \mathrm{l}$ sodium pyruvate and
L-glutamine, and $10 \%$ fetal bovine serum (FBS). The cells were maintained in an NU-5810 incubator (IBS Tecnomara, Fernwald, Germany) at $37^{\circ} \mathrm{C}$ with a $5 \% \mathrm{CO}_{2}$ atmosphere. The cells were then sub-cultured at $\sim 90 \%$ confluence by detaching with $0.25 \%$ trypsin and 0.03\% EDTA (SigmaAldrich). Test compounds with or without the protease inhibitor (final concentration $0.0007 x$ ) were dissolved in water and diluted in DMEM. One day before each experiment, cells were plated at a density of $8 \times 10^{4}$ cells/ $\mathrm{ml}$ in Cell Star 96-well plates (Greiner Bio-One, Frickenhausen, Germany). The cells were rinsed with PBS before adding $100 \mu$ l of the test compound and incubating for $3.5 \mathrm{~h}$ at $37^{\circ} \mathrm{C}$. Test compounds were then removed and the cells were rinsed with PBS before staining with $10 \% \mathrm{v} / \mathrm{v}$ AlamarBlue (Bio-Rad, Puchheim, Germany) in DMEM for $2 \mathrm{~h}$. The fluorescence was measured using an Eon microplate reader (BioTek, Winooski, Vermont, USA) using excitation and emission wavelengths of 528 and $590 \mathrm{~nm}$, respectively. Cells exposed to DMEM without test compounds were used as a negative control and DMEM only was used as a blank reference. Percentage cytotoxicity of the test compounds was calculated in comparison to the negative control.

\section{UPEC-G. mellonella infection model and protease assay}

We analyzed the survival of UPEC strain CFT073 in infected G. mellonella larvae. ${ }^{6}$ Briefly, larvae were homogenized in LB medium $1 \mathrm{~h}$ post injection and plated onto E. coli selective "E. coli direct" (ECD) agar (Sigma-Aldrich). The plates were incubated at $37^{\circ} \mathrm{C}$ for $24 \mathrm{~h}$ and the colonies were counted. To confirm the presence of $E$. coli colonies, an indole test was performed using Kovac's reagent (Sigma-Aldrich) according to the manufacturer's protocol.

For the analysis of infected larvae survival, logarithmic UPEC CFT073 cultures with a density of $10^{9} \mathrm{CFU} / \mathrm{ml}$ in $10 \mathrm{ml} \mathrm{LB}$ medium were washed and serially diluted in $0.9 \% \mathrm{NaCl}$ to appropriate concentrations. To calculate the CFU of the inoculum, $50 \mu \mathrm{l}$ of the injection dilution was plated on LB agar and incubated at $37^{\circ} \mathrm{C}$ for $24 \mathrm{~h}$. We then injected $10 \mu \mathrm{l}$ of the bacterial inoculum $\left(10^{6} \mathrm{CFU} / \mathrm{ml}\right)$ dorsolaterally into the hemocoel of lastinstar larvae. ${ }^{21}$ After incubating at $37^{\circ} \mathrm{C}$ for $30 \mathrm{~min}$, we injected the test compounds with or without the protease inhibitor. Larvae were considered dead when they showed no tactile response after incubation at $37^{\circ} \mathrm{C}$ for 5 days.

Last-instar larvae were injected with $10 \mu$ of the protease inhibitor cocktail described above and were incubated at room temperature for 1 or $3 \mathrm{~h}$ before pricking the integument and withdrawing $100 \mu \mathrm{l}$ of hemolymph. The hemolymph was centrifuged at $870 \times g$ for $10 \mathrm{~min}$ at $4{ }^{\circ} \mathrm{C}$. The supernatant was transferred to a black 96 -well plate on ice. A Pierce Fluorescence Protease Assay Kit (Thermo Fisher Scientific) was then used to measure protease activity according to the manufacturer's instructions. The intensity of fluorescein fluorescence was measured using a monochromator-based microplate reader (BioTek) with excitation and emission wavelengths of 485 and $538 \mathrm{~nm}$, respectively. The work involving invertebrates such as $G$. mellonella does not need ethical permission according to German law.

Reverse transcription polymerase chain reaction (RT-PCR) analysis of metabolic gene expression

Complementary DNA was synthesized using the First-strand complementary DNA (cDNA) Synthesis Kit (Thermo Fisher Scientific). The CDNA concentration was determined by spectrophotometry. Quantitative realtime RT-PCR was performed using the CFX 96 real-time PCR system (BioRad Laboratories, Hercules, California, USA) and a SensiMix SYBR No-ROX kit (Bioline, Luckenwalde, Germany). We used $50 \mathrm{ng}$ of cDNA per reaction to amplify gene sequences related to drug metabolism phases I and III using the primers shown in Supplementary Table 5. The amplification parameters comprised an initial activation step at $95^{\circ} \mathrm{C}$ for $10 \mathrm{~min}$, followed by 39 cycles of denaturation at $95^{\circ} \mathrm{C}$ for $15 \mathrm{~s}$, annealing at $56^{\circ} \mathrm{C}$ for $15 \mathrm{~s}$ and extension at $72^{\circ} \mathrm{C}$ for $15 \mathrm{~s}$. The relative expression levels of the target genes were determined using the $\triangle \Delta C T$ method and the gene encoding $18 \mathrm{~S}$ ribosomal RNA for data normalization.

Live and dead staining of bacteria exposed to antimicrobial compounds

UPEC strain CFT073 was cultured at $37^{\circ} \mathrm{C}$ until the cells reached the logarithmic growth phase. The cells were harvested and washed in PBS, and then a suspension of $\sim 10^{3} \mathrm{CFU} / \mathrm{ml}$ was treated with an equal volume of CecA $(50 \mu \mathrm{g} / \mathrm{ml})$, NAL $(0.5 \mathrm{ng} / \mathrm{ml})$, a combination $(50 \mu \mathrm{g} / \mathrm{ml} \mathrm{CecA}+$ 
$0.5 \mathrm{ng} / \mathrm{ml} \mathrm{NAL}$ ), or the negative control (1\% PBS). After incubating at $37^{\circ} \mathrm{C}$ for $3 \mathrm{~h}$, the cultures were harvested and stained with $0.3 \%$ SYTO 9 and propidium iodide at ratio of 1:1 from the Live/Dead BacLight bacterial viability and counting kit (Thermo Fisher Scientific, Waltham, Massachusetts, USA). After mixing, the samples were mounted on microscope slides and observed using a Leica fluorescent microscope with diode lasers (excitation and emission wavelengths 488 and $561 \mathrm{~nm}$, respectively).

\section{Bacterial membrane permeabilization assay}

The membrane permeabilizing activity of the peptides was determined on the basis of a $\beta$-galactosidase activity level using the E. coli JM83 cells bearing plasmid $\mathrm{pCH} 110$ (Pharmacia-Amersham, Piscatway, NJ, USA), encoding constitutively synthesized cytoplasmic $\beta$-galactosidase. ${ }^{22}$ Briefly, the peptide was pre-incubated for $15 \mathrm{~min}$ at $37^{\circ} \mathrm{C}$ in $20 \mathrm{mM}$ phosphate buffer pH $6.8(23 \mu \mathrm{l})$. Then, $2 \mu \mathrm{l}$ of mid-logarithmic phase E. coli cells suspension $\left(5 \times 10^{5} \mathrm{CFU}\right)$ in the same buffer were added. After $45 \mathrm{~min}$ incubation at $37^{\circ} \mathrm{C} 20 \mathrm{mM} \mathrm{HEPES} / 150 \mathrm{mM} \mathrm{NaCl}$ buffer pH $7.5(220 \mu \mathrm{l})$ and $50 \mathrm{mM}$ aqueous solution of $p$-nitrophenyl- $\beta$-D-galactopyranoside $(5 \mu \mathrm{l})$ were added. The absorbance proportional to the $\beta$-galactosidase activity was measured at $405 \mathrm{~nm}$ after $1.5 \mathrm{~h}$ incubation at $37^{\circ} \mathrm{C}$. Live bacteria incubated alone and dead bacteria after treatment with $5 \mu \mathrm{M}$ synthetic cecropin B (Sigma-Aldrich) served as the control samples. The permeabilization level of the dead bacteria was assumed as $100 \%$. All assays were performed in triplicate in six independent experiments.

\section{Atomic force microscopy (AFM) imaging}

Log-phase E. coli JM83 suspension $(100 \mu \mathrm{l})\left(\mathrm{OD}_{600}=0.2\right)$ in the $\mathrm{LB}$ were incubated for $1.5 \mathrm{~h}$ at $37^{\circ} \mathrm{C}$ without (control) and in the presence of the CecA (the final concentrations $0.25 \mu \mathrm{M}$ ). ${ }^{22,23}$ Next, the samples were centrifuged at $8000 \times g$ for $10 \mathrm{~min}$ at $4{ }^{\circ} \mathrm{C}$ and washed twice with nonpyrogenic water. After final centrifugation, the bacteria were suspended in non-pyrogenic water $(5 \mu \mathrm{l})$, applied on mica disks, and the samples were allowed to dry overnight at $28^{\circ} \mathrm{C}$.

Bacterial cell surface was imaged using NanoScope V AFM (Veeco, USA). A ScanAsyst-HR operation mode was used for topography imaging, as well as for the roughness and adhesion analyses measurements, whereas for Young's modulus analysis the PeakForce QNM operation mode was applied. All measurements were done using a RTESPA silicon tip with a spring constant of $20 \mathrm{~N} / \mathrm{m}$ (Bruker, Germany). The data were analyzed with Nanoscope Analysis ver. 1.40 software (Veeco, USA). Three fields on each mica disk were imaged. The Young's modulus values were calculated from five $500 \times 500 \mathrm{~nm}$ images. The average surface root-mean-square (RMS) roughness and adhesion values were calculated from sixty fields $(80 \times$ $80 \mathrm{~nm}$ ) measured over the entire bacterial cell surface on $500 \mathrm{~nm} \times 500 \mathrm{~nm}$ areas. Three dimensional images and section profiles were done using WSxM 5.0 software. $^{23}$

\section{Determination of degradation/inhibition of UPEC biofilms by crystal violet assay}

Logarithmic bacterial cultures were cultivated in LB medium supplemented with $0.8 \%$ glucose at $37^{\circ} \mathrm{C}$, without shaking, in 96-well plates $\left(\sim 5 \times 10^{7}\right.$ cells/well) to initiate biofilm formation. Different strategies were adopted for analyzing the inhibition and degradation of UPEC biofilms in the presence of test compounds. The inhibition of biofilm formation was assayed by incubating UPEC strain CFT073 and 536 with test compounds (CecA, NAL, or CecA + NAL) for $48 \mathrm{~h}$. To access biofilm degradation, UPEC was cultivated for $18 \mathrm{~h}$ to initiate biofilm formation. The culture medium and non-bound bacteria were removed by washing three times with sterile water, and attached cells were resuspended in LB medium supplemented with $0.8 \%$ glucose and the test compounds (CecA, NAL, or CecA + NAL) and incubated for another $18 \mathrm{~h}$. The culture medium was discarded, and the wells were washed three times with sterile water before staining with $0.1 \%$ crystal violet for $30 \mathrm{~min}$. Excess stain was removed by three washes with sterile water. The biofilm-bound crystal violet was solubilized by adding $130 \mu \mathrm{l} 30 \%$ acetic acid and quantified by spectrophotometry at $570 \mathrm{~nm}$.

\section{Determination of viable numbers of UPEC biofilm cells by plate count}

UPEC strains CFT073 and 536 were cultivated in LB medium supplemented with $0.8 \%$ glucose and incubated with the test compounds (CecA, NAL, or CecA + NAL) for $24 \mathrm{~h}$ without shaking. The biofilm-forming UPEC cells with and without the antimicrobials were suspended and homogenized in LB via scraping and vortexing. Serial dilutions of the bacterial cultures were plated onto LB agar, and CFUs were counted after $24 \mathrm{~h}$ incubation.

\section{Electron microscopy}

For transmission electron microscopy (TEM), test and control groups of bacteria were fixed with $3 \%$ formaldehyde and $0.5 \%$ glutaraldehyde in $0.1 \mathrm{M}$ cacodylate buffer, embedded in gelatin (Sigma-Aldrich), post-fixed in $1.5 \%$ osmium tetroxide in the same buffer, washed with the buffer and incubated in $1 \%$ aqueous uranyl acetate (PolySciences, Niles, Illinois, USA) overnight at $4{ }^{\circ} \mathrm{C}$. Specimens were dehydrated in an ethanol series $(30,50$, 70, 80, 90, 96, 100\% (v/v), 20 min each) and embedded in Epon (Serva Electrophoresis, Heidelberg, Germany). After heat curing, sliver to gold ultrathin sections were cut and contrasted in uranyl acetate and lead citrate. Ultrathin sections were visualized using an EM912a/b TEM (Carl Zeiss, Oberkochen, Germany) at $120 \mathrm{kV}$ under zero-loss conditions and images were recorded with slight underfocus using a cooled $2 \mathrm{k} \times 2 \mathrm{k}$ slowscan charge-coupled device camera and the iTEM package (Olympus Soft Imaging Solutions, Münster, Germany). ${ }^{24}$

For scanning electron microscopy (SEM) analysis of bacterial surface, cells were grown on discs and after test and control treatment the specimens were fixed, post-fixed, washed, and dehydrated in an ethanol series as above. After critical point drying, the cells were mounted on SEM holders and sputtered with gold. Samples were observed in a DSM982 field emission gun scanning electron microscope (Carl Zeiss) at 3-5 kV. Images were recorded using a secondary electron detector with the voltage of the collector grid biased to $+300 \mathrm{~V}$ in order to improve the signal-to-noise ratio and achieve an optimal topographical contrast. ${ }^{24}$

\section{Bacterial adaptation to antimicrobial compounds}

The ability of UPEC CFT073 cells to adapt to NAL or the NAL + CecA combination was tested using the microdilution method described above. Cells at an $\mathrm{OD}_{600}$ of $\sim 0.002$ were exposed to a sub-inhibitory concentration of NAL $(20 \mu \mathrm{g} / \mathrm{ml})$ for $24 \mathrm{~h}$, then they were diluted to $\mathrm{OD}_{600} \sim 0.002$ in fresh LB medium supplemented with the same concentration of NAL for a further $24 \mathrm{~h}$. This process of serial passaging and exposure was continued for 5 days. Similarly, cells were exposed to a sub-inhibitory concentration of the combination of NAL $(0.5 \mathrm{ng} / \mathrm{ml})$ and CecA $(20 \mu \mathrm{g} / \mathrm{ml})$ for 5 days. Absorbance was measured at $600 \mathrm{~nm}$ to determine growth.

\section{Accumulation assay}

UPEC strain CFT073 was used to develop and evaluate an assay based on the intracellular accumulation of the fluorescent probe $\mathrm{H} 33342$ bisbenzimide (Sigma-Aldrich). ${ }^{12}$ The toxicity of H33342 $(2.5 \mu \mathrm{M})$ was determined by the incubation of CFT073 at a mid-log growth phase $\mathrm{OD}_{600}$ of 0.6 for $24 \mathrm{~h}$, and bacterial growth was determined using a plate reader (BioTek).

Planktonic bacterial strains were grown at an exponential growth phase $\mathrm{OD}_{600}$ of $0.6\left(=10^{8} \mathrm{CFU} / \mathrm{ml}\right)$ with aeration in $\mathrm{LB}$ at $37^{\circ} \mathrm{C}$. Bacteria were also cultivated for $24 \mathrm{~h}$ in LB medium supplemented with $0.8 \%$ glucose at $37^{\circ} \mathrm{C}$, without shaking to initiate biofilm formation. UPEC biofilms were suspended and homogenized in LB via scraping and vortexing. Planktonic and biofilm cells were harvested by centrifugation at $2100 \times g$ for $2 \mathrm{~min}$ at room temperature and resuspended in $1 \mathrm{ml}$ PBS. The $\mathrm{OD}_{600}$ of the suspension was measured and adjusted to 0.5 to standardize the number of cells in each culture and to simulate the conditions used in the $\mathrm{H} 33342$ accumulation assay. A $180-\mu \mathrm{l}$ aliquot of bacterial culture was supplemented with CecA ( $1 \mu \mathrm{g} / \mathrm{ml}$ for planktonic cells and $10 \mu \mathrm{g} / \mathrm{ml}$ for biofilm cells) or NAL $(0.5 \mathrm{ng} / \mathrm{ml})$ and $20 \mu \mathrm{L} \mathrm{H} 33342(2.5 \mu \mathrm{M})$ in the wells of a black microtiter plate, with PBS as a negative control. Fluorescence intensity was measured (excitation and emission wavelengths of 335 and $460 \mathrm{~nm}$, respectively) after incubating at $37^{\circ} \mathrm{C}$. Raw fluorescence values were analyzed using Microsoft Excel (Microsoft, Redmond, Washington, USA), including the calculation of mean values for each column and the subtraction of blanks.

\section{Efflux assay}

An overnight culture of the UPEC strain was diluted and grown to exponential phase (planktonic cells). Similarly, an overnight culture of the UPEC strain was diluted and grown in LB medium supplemented with $0.8 \%$ glucose at $37^{\circ} \mathrm{C}$ for $24 \mathrm{~h}$, without shaking to initiate biofilm formation. UPEC biofilms were collected in LB via scraping and vortexing. Aliquots of the culture were centrifuged at $2100 \times g$ for $10 \mathrm{~min}$ at room temperature. 
The pellet was resuspended in $20 \mathrm{mM}$ PBS (pH 7.4) containing $1 \mathrm{mM}$ $\mathrm{MgCl}_{2}$. After another centrifugation and resuspension step as above, the cells were adjusted to an $\mathrm{OD}_{600}$ of 1.0 in PBS. All subsequent operations were carried out at room temperature, except as noted. The cells were allowed to rest for $\sim 20 \mathrm{~min}$, and $500-\mu \mathrm{l}$ aliquots were then transferred to Pyrex $15-\mathrm{ml}$ conical centrifugation tubes (glass tubes were used because Nile red is adsorbed to the walls of plastic tubes). Aliquots of this culture were supplemented with CecA $(1 \mu \mathrm{g} / \mathrm{ml}$ for planktonic cells and $10 \mu \mathrm{g} / \mathrm{ml}$ for biofilm cells) or NAL $(0.5 \mathrm{ng} / \mathrm{ml})$ in glass test tubes and incubated at $37^{\circ} \mathrm{C}$ for $20 \mathrm{~min}$. Untreated CFT073 cells were used as a negative control. After $20 \mathrm{~min}$, Nile red stock solution $(1 \mathrm{mM}$ in 9:1 (v/v) ethanol: dimethylformamide) was added to a final concentration of $1 \mu \mathrm{M}$, and the cell suspension was incubated at $37^{\circ} \mathrm{C}$ for $1 \mathrm{~h}$. After centrifugation at $2100 \times g$ for $5 \mathrm{~min}$ at room temperature, most of the supernatant was discarded, and droplets clinging to the tube wall were removed using absorbent tissues. The cells were resuspended in $2 \mathrm{ml}$ PBS and fluorescence was measured using a microplate reader (BioTek) at excitation and emission wavelengths of 544 and $650 \mathrm{~nm}$, respectively, with and without glucose $(20 \mathrm{mM})$, which triggers efflux in bacteria. We analyzed Nile red efflux at three glucose concentrations $(50,20$, and $10 \mathrm{mM}$ ) and selected $20 \mathrm{mM}$ for meaningful quantification of UPEC efflux potential (Supplementary Fig. 7c).

Data from experiments for normalization of dye fluorescence (y-axis) versus time ( $x$-axis) were plotted using GraphPad Prism v7.05 (GraphPad Software, La Jolla, California, USA). The Nile red and treated curves were fitted using a single exponential decay (one phase decay) equation:

$Y=\left(Y_{0}-\right.$ plateau $) \times \exp (-K \times X)+$ plateau

where $X$ is the time, and $Y$ starts at $Y_{0}$ and then decays in one phase down to plateau. The plateau is the $Y$ value at infinite time. The span is the difference between $Y_{0}$ and the plateau and has the same units as $Y . K$ is the rate constant. ${ }^{25}$

DNA/RNA/eDNA-binding, gyrase, and DnaK ATPase activity assays UPEC strain CFT073 genomic DNA/total RNA was extracted using the bacterial genomic DNA extraction kit (Sigma-Aldrich) and RNeasy Mini Kit (Qiagen, Hilden, Germany), and $20 \mu \mathrm{l}$ of the purified genomic DNA $(2.76 \mu \mathrm{g})$ was incubated with CecA or NAL for $1 \mathrm{~h}$ at room temperature. RNA binding was measured by incubating CecA or NAL with total RNA $(13 \mu \mathrm{g})$ on ice for $1 \mathrm{~h}$. We then added $2 \mu \mathrm{l}$ of native loading buffer, and a $10-\mu \mathrm{l}$ aliquot was separated by $1 \%$ agarose gel electrophoresis in $1 \times$ Trisborate-EDTA buffer ( $45 \mathrm{mM}$ Tris-borate, $1 \mathrm{mM}$ EDTA, pH 8.0). All gels were derived from the same experiment and were processed in parallel (Supplementary Figs 8 and 9).

The eDNA-binding assay was developed by inoculating CFT073 at $\mathrm{OD}_{600}=0.04$ in $250 \mu \mathrm{LB}$ medium supplemented with $0.2 \mu \mathrm{M}$ BOBO-3 (Thermo Fisher Scientific), a non-cell-permeable cyanine-based DNA dye, which has high affinity for nucleic acids and fluoresces strongly when bound to nucleic acids but not in their absence. The bacteria were grown for $24 \mathrm{~h}$ in the presence of CecA, NAL, CecA + NAL, or Tris-buffered saline (control) in black, F-bottom 96-well plates (Greiner Bio-One) at $37{ }^{\circ} \mathrm{C}$ with slight orbital shaking. A well-area scan was carried out at hourly intervals for $21 \mathrm{~h}$ to detect eDNA fluorescence at excitation and emission wavelengths of 570 and $602 \mathrm{~nm}$, respectively, in a Synergy H4 Hybrid Multi-Mode plate reader (BioTek). The readout was presented in relative fluorescence units (RFU).

CecA was predicted to bind to the WKIFKKI sequence of DnaK (http:// limbo.switchlab.org). The E. coli gyrase ATPase activity was determined using the E. coli gyrase ATPase Assay Kit Plus (ProFoldin, Hudson, Massachusetts, USA). Briefly, the $30-\mu l$ reaction mixture composed of $15 \mu \mathrm{l}$ of water, $3 \mu \mathrm{l}$ of sample/standard at various concentrations, $3 \mu \mathrm{l}$ of $10 \times$ buffer, $3 \mu \mathrm{l}$ of $10 \times \mathrm{DNA}, 3 \mu \mathrm{l}$ of $10 \times E$. coli DNA gyrase (enzyme) or $5 \mu \mathrm{g}$ recombinant $E$. coli DnaK protein (Abcam, Cambridge, UK) and $3 \mu \mathrm{l}$ of $2 \mathrm{mM}$ ATP. A reaction mixture without CecA/NAL was used as positive control. A reaction mixture without DNA gyrase or DnaK was used as the negative control. The reaction mixture was incubated at $37^{\circ} \mathrm{C}$ (DNA gyrase ATPase activity) or $25^{\circ} \mathrm{C}$ (DnaK ATPase activity) for $60 \mathrm{~min}$. After incubation, $45 \mu \mathrm{l}$ of the dye supplied with the kit was added and the absorbance was measured at $650 \mathrm{~nm}$ using a Synergy H4 Hybrid MultiMode plate reader (BioTek).
Data analysis

Data were analyzed using GraphPad Prism v7.05 and Microsoft Excel 2013. All experiments were carried out a minimum of three times. Significant differences between pairs of values were compared using one-way analysis of variance (ANOVA) with Dunnett's multiple comparison test, Mann-Whitney U-test, and Holm-Šídák test.

\section{Reporting summary}

Further information on experimental design is available in the Nature Research Reporting Summary linked to this article.

\section{DATA AVAILABILITY}

The authors declare that [the/all other] data supporting the findings of this study are available within the paper [and its supplementary information files].

Received: 12 September 2019; Accepted: 15 January 2020; Published online: 12 February 2020

\section{REFERENCES}

1. Flores-Mireles, A. L., Walker, J. N., Caparon, M. \& Hultgren, S. J. Urinary tract infections: epidemiology, mechanisms of infection and treatment options. Nat. Rev. Microbiol. 13, 269-284 (2015).

2. Toval, F. et al. Characterization of Escherichia coli isolates from hospital inpatients or outpatients with urinary tract infection. J. Clin. Microbiol. 52, 407-418 (2014).

3. Koo, H., Howlin, R. P., Stoodley, P. \& Hall-Stoodley, L. Targeting microbial biofilms: current and prospective therapeutic strategies. Nat. Rev. Microbiol. 15, 740-755 (2017).

4. Yu, G., Baeder, D. Y., Regoes, R. R. \& Rolff, J. Predicting drug resistance evolution: insights from antimicrobial peptides and antibiotics. Proc. Biol. Sci. 285, pii: 20172687 (2018)

5. Zheng, Z. et al. Synergistic efficacy of Aedes aegypti antimicrobial peptide cecropin A2 and tetracycline against Pseudomonas aeruginosa. Antimicrob. Agents Chemother. 61, pii: e00686-17 (2017).

6. Heitmueller, M., Billion, A., Dobrindt, U., Vilcinskas, A. \& Mukherjee, K. Epigenetic mechanisms regulate innate immunity against uropathogenic and commensallike Escherichia coli in the surrogate insect model Galleria mellonella. Infect. Immun. 85, pii: e00336-17 (2017).

7. Shin, Y. P. et al. Antimicrobial activity of a halocidin-derived peptide resistant to attacks by proteases. Antimicrob. Agents Chemother. 54, 2855-2866 (2010).

8. Yan, J. et al. Two hits are better than one: membrane-active and DNA bindingrelated double-action mechanism of NK-18, a novel antimicrobial peptide derived from mammalian NK-lysin. Antimicrob. Agents Chemother. 57, 220-228 (2013).

9. Marr, A. K., Gooderham, W. J. \& Hancock, R. E. Antibacterial peptides for therapeutic use: obstacles and realistic outlook. Curr. Opin. Pharmacol. 6, 468-472 (2006).

10. Hall, C. W. \& Mah, T. F. Molecular mechanisms of biofilm-based antibiotic resistance and tolerance in pathogenic bacteria. Fems. Microbiol. Rev. 41, 276-301 (2017).

11. Devaraj, A., Justice, S. S., Bakaletz, L. O. \& Goodman, S. D. DNABII proteins play a central role in UPEC biofilm structure. Mol. Microbiol. 96, 1119-1135 (2015).

12. Coldham, N. G., Webber, M., Woodward, M. J. \& Piddock, L. J. A 96-well plate fluorescence assay for assessment of cellular permeability and active efflux in Salmonella enterica serovar typhimurium and Escherichia coli. J. Antimicrob. Chemother. 65, 1655-1663 (2010).

13. Alav, I., Sutton, J. M. \& Rahman, K. M. Role of bacterial efflux pumps in biofilm formation. J. Antimicrob. Chemother. 73, 2003-2020 (2018).

14. Blair, J. M. \& Piddock, L. J. How to measure export via bacterial multidrug resistance efflux pumps. MBio 7, pii: e00840-16 (2016).

15. Nakao, R., Myint, S. L., Wai, S. N. \& Uhlin, B. E. Enhanced biofilm formation and membrane vesicle release by Escherichia coli expressing a commonly occurring plasmid gene, kil. Front. Microbiol. 9, 2605 (2018).

16. Ogata, Y. et al. DnaK heat shock protein of Escherichia coli maintains the negative supercoiling of DNA against thermal stress. J. Biol. Chem. 271, 29407-29414 (1996).

17. Orhan, G., Bayram, A., Zer, Y. \& Balci, I. Synergy tests by E test and checkerboard methods of antimicrobial combinations against Brucella melitensis. J. Clin. Microbiol. 43, 140-143 (2005). 
18. Johnson, M. D. et al. Combination antifungal therapy. Antimicrob. Agents Chemother. 48, 693-715 (2004).

19. Tonk, M. et al. Antiplasmodial activity of tick defensins in a mouse model of malaria. Ticks Tick. Borne Dis. 9, 844-849 (2018).

20. Luna-Ramirez, K., Tonk, M., Rahnamaeian, M. \& Vilcinskas, A. Bioactivity of natural and engineered antimicrobial peptides from venom of the scorpions Urodacus yaschenkoi and U. manicatus. Toxins 9, pii: E22 (2017).

21. Mukherjee, K., Hain, T., Fischer, R., Chakraborty, T. \& Vilcinskas, A. Brain infection and activation of neuronal repair mechanisms by the human pathogen Listeria monocytogenes in the lepidopteran model host Galleria mellonella. Virulence 4, 324-332 (2013).

22. Zdybicka-Barabas, A. et al. Synergistic action of Galleria mellonella apolipophorin III and lysozyme against Gram-negative bacteria. Biochim. Biophys. Acta 1828, 1449-1456 (2013).

23. Horcas, I. et al. WSxM: a software for scanning probe microscopy and a tool for nanotechnology. Rev. Sci. Instrum. 78, 013705 (2007).

24. Glaeser, S. P. et al. Non-pathogenic Rhizobium radiobacter F4 exhibits plant beneficial activity independent of its host Piriformospora indica. ISME J. 10, 871-884 (2016).

25. Iyer, R., Ferrari, A., Rijnbrand, R. \& Erwin, A. L. A fluorescent microplate assay quantifies bacterial efflux and demonstrates two distinct compound binding sites in AcrB. Antimicrob. Agents Chemother. 59, 2388-2397 (2015).

\section{ACKNOWLEDGEMENTS}

We acknowledge Richard M. Twyman for professional editing of the manuscript and Rolf Hirsch, Sabine Agel, and Anna Moebus for technical support. K.M. acknowledges funding provided by the German Research Foundation (MU 4008/1-1). U.D. received support from the German Research Foundation (SFB1009, TP B05). The funders had no role in study design, data collection and interpretation, or the decision to submit the work for publication.

\section{AUTHOR CONTRIBUTIONS}

K.M. designed research; K.M., M.K., M.T., M.H., A.Z.-B., M.C. performed research; M.K., K.M, M.T., M.H., U.D., A.Z.-B, M.C. analyzed data; A.V., K.M., U.D. wrote and revised the paper. All authors approved the final version of the paper. K.M. and M.K. contributed equally to this work and are co-first authors.

\section{COMPETING INTERESTS}

The authors declare no competing interests.

\section{ADDITIONAL INFORMATION}

Supplementary information is available for this paper at https://doi.org/10.1038/ s41522-020-0116-3.

Correspondence and requests for materials should be addressed to A.V. or K.M.

Reprints and permission information is available at http://www.nature.com/ reprints

Publisher's note Springer Nature remains neutral with regard to jurisdictional claims in published maps and institutional affiliations.

(c) (i)

Open Access This article is licensed under a Creative Commons Attribution 4.0 International License, which permits use, sharing, adaptation, distribution and reproduction in any medium or format, as long as you give appropriate credit to the original author(s) and the source, provide a link to the Creative Commons license, and indicate if changes were made. The images or other third party material in this article are included in the article's Creative Commons license, unless indicated otherwise in a credit line to the material. If material is not included in the article's Creative Commons license and your intended use is not permitted by statutory regulation or exceeds the permitted use, you will need to obtain permission directly from the copyright holder. To view a copy of this license, visit http://creativecommons. org/licenses/by/4.0/.

(c) The Author(s) 2020 